\title{
CULTURA, POLÍTICA E DIREITOS NO CANAVIAL DA DITADURA MILITAR BRASILEIRA
}

\author{
Culture, politics and rights in the sugar cane \\ fields of Brazilian military dictatorship
}

\author{
TIAGO MARTINS SimÕES E \\ RICARDO JOSÉ DE AZEVEDO MARINHO
}

http://dx.doi.org/10.1590/S0103-21862015000200007

Tiago Martins Simões é doutorando do Programa de Pós-Graduação em História, Política e Bens Culturais (PPHPBC) do CPDOC-FGV (tiagorj@gmail.com).

Ricardo José de Azevedo Marinho é professor pós-doutor da Escola de Educação, Ciências, Letras, Artes e Humanidades da Universidade do Grande Rio (UNIGRANRIO) e assessor da presidência da Companhia Estadual de Águas e Esgotos (CEDAE) (ricardo.marinho@cedae.com.br).

Artigo recebido em 31 de julho e aprovado para publicação em 29 de setembro de 2015. 


\title{
RESUMO
}

Este artigo analisa a reestruturação do trabalho no canavial brasileiro no contexto da ditadura militar brasileira de 1964 a partir de uma perspectiva dos processos de longa duração. Para isso, buscamos evidenciar as principais transformaç̃̃es dessa formação econômico-social a partir da revolução de 1930, que possibilitam uma compreensão da desproteção social dos trabalhadores e trabalhadoras canavieiras, situando a ditadura militar como um dos eixos de uma revolução passiva que encontrou sedimentações do passado, deixando ao mesmo tempo, no presente, vestígios dos dias de um futuro esquecido de nossa história.

Palavras-CHAVE: cana-de-açúcar; ditadura militar; reestruturação do trabalho; desproteção social.

\begin{abstract}
This article analyzes the restructuring of work in Brazilian sugarcane fields in the context of the Brazilian military dictatorship of 1964 from a perspective of long-term processes. For this, we seek to highlight the main changes in this socioeconomic structure from the 1930 revolution, which allow an understanding of the lack of social protection of sugarcane workers, placing the military dictatorship as an axes of a passive revolution that found sedimentation of the past, while leaving, at present, vestiges of the days of a future forgotten in our history.
\end{abstract}

KEY-WORDS: sugarcane; military dictatorship; restructuring of work; lack of social protection.

\section{RÉSUMÉ}

Cet article analyse la restructuration du travail de la canne à sucre brésilienne pendant la dictature militaire brésilienne de 1964 dans une perspective de processus à long terme. Pour cela, nous cherchons à mettre en évidence les principaux changements de cette structure socio-économique a partir de la révolution de 1930, qui permettent la compréhension de l'absence de protection sociale des travailleurs de la canne à sucre, plaçant la dictature militaire comme un des axes d'une révolution passive qui a trouvé la sédimentation du passé, tout en laissant, à l'heure actuelle, les vestiges des jours d'un avenir oublié de notre histoire.

MoTS-CLÉs: canne à sucre; dictature militaire; reestructuration du travail; absence de protection sociale. 
ratar do tema do canavial no contexto brasileiro da ditadura de 1964 é um desafio bastante complexo, a começar pelo critério de demarcação deste fatídico ano. Isto porque, apesar das reconhecidas mudanças produzidas a partir de então, em especial no regime político, podemos destacar inúmeras outras mudanças e permanências que atravessaram o período e que nos vinham de longa data, em especial desde 1930. Assim, a chegada da ditadura não representou uma ruptura absoluta com relação ao período que a literatura consagra como o pré-1964; da mesma forma, a redemocratização da década de 1980, coroada com a moderna e cidadã Constituição Federal de 1988, não eclipsou plenamente as heranças do regime, especialmente no tocante ao mundo do trabalho rural, conforme buscaremos demonstrar.

A história da desproteção social do trabalho no canavial brasileiro foi elaborada neste artigo tomando como base teórica o conceito de revolução passiva, ${ }^{1}$ a partir de sua releitura para a realidade brasileira elaborada por Werneck Vianna (2004), que possui muitas aproximações com a perspectiva da "história lenta" da teoria social de Martins (1994). Com este viés interpretativo, buscamos analisar empiricamente, através da historiografia e da sociologia do tema e de análises documentais da legislação do período, como se desenhou a (re)estruturação das relações de trabalho rural no canavial brasileiro com duas chaves analíticas: uma de longa duração, em que estruturas e relações do passado condicionam e, ao mesmo tempo, transformam as subsequentes; outra, a da relação entre sociedade e Estado, buscando evidenciar a dificuldade de se compreender uma dessas variáveis sem a presença da outra.

0 artigo está dividido em quatro partes. Na primeira, apresentamos um preâmbulo das políticas que dirigiram a formação da economia canavieira, indicando a impossibilidade de se compreender o processo sem colocar o foco no Estado e nos arranjos corporativos, na relação deste com as classes economicamente dominantes. Nesta chave conseguimos tornar inteligível a transferência do eixo produtivo nacional da região Nordeste para a região Centro-Sul, notadamente para o estado de São Paulo. Em seguida, ainda a título de preâmbulo, aproximamos a análise da experiência da cana no município de Campos dos Goytacazes (RJ), região que, ao mesmo tempo em que se beneficiou da mudança de eixo produtivo, apresentou dificuldades econômicas, não chegando a se consolidar como produtora nos moldes das 
regiões situadas no estado de São Paulo e constituindo, portanto, uma experiência híbrida. Aqui, o interesse maior é o de explorar dois aspectos da história e da sociologia do trabalho: a reestruturação do trabalho e a desproteção social.

Os dois itens seguintes seguem uma estrutura análoga à dos dois primeiros. Na seção "A ditadura no canavial brasileiro" voltamos a discutir o aspecto das políticas de Estado em nível federal - mas já na chave da ditadura de 1964 -, destacando a nova correlação de forças que passou a existir entre o capital agroindustrial (especialmente dos usineiros paulistas) e as políticas modernizadoras, que teriam enorme impulso econômico a partir do nexo criado com o álcool na década de 1970. No tópico seguinte, analisamos novamente o aspecto do trabalho na reestruturação produtiva do período, defendendo a ideia de que, a partir daí, não por acaso, criou-se a estrutura jurídica e institucional das relações de trabalho do assalariado rural vigentes até hoje, tendo como figura típica os cortadores e cortadoras de cana, figura essa que, ao mesmo tempo em que se constitui como nova no modo de produção, carrega consigo o peso das sedimentações passivas de um passado esquecido.

\section{O PREÂMBULO INTERNACIONAL \& NACIONAL DO CANAVIAL}

importância dos arranjos corporativos no nexo dos usineiros da economia canavieira
com o Estado, para que este mediasse a formulação das políticas do setor, é uma marca constituinte percebida desde os primeiros anos da década de 1930. A partir da crise de 1929, as elites produtoras rurais da cana recorreram à intervenção estatal, que por sua vez teve como primeira manifestação o Decreto Federal n²0.761, de 7 de dezembro de 1931, que criou a Comissão de Defesa da Produção de Açúcar para garantir o preço do produto no mercado interno.

0 planejamento sistemático do Estado nesta economia, no entanto, começou com o Decreto Federal $n^{\circ} 22.789$, de $1^{\circ}$ de junho de 1933, que criou a autarquia Instituto do Açúcar e do Álcool (IAA) para que esta realizasse a "defesa" dos preços do açúcar no mercado interno, regulando a oferta do produto a partir da formação de um estoque. Para não provocar a queda do preço do produto, os excedentes da demanda interna deveriam ser evacuados de duas formas: pela exportação ou pela transformação do açúcar em álcool. Quanto a este último produto, no intuito de estimular sua produção, foram outorgados benefícios para a construção de destilarias anexas às usinas de açúcar. A instalação de algumas destilarias de grande porte e o monopólio da comercialização do álcool era de responsabilidade do IAA; não por acaso, data dessa época a obrigação de adicionar 5\% de álcool à gasolina importada, nos termos Decreto Federal n 19.717 de 20 de fevereiro de 1931. 
Além dos ajustes da produção, o IAA teria também um papel importante na tentativa de acomodação de conflitos entre as diversas classes participantes da economia sucroalcooleira, especialmente entre os usineiros e fornecedores, marcantes no Nordeste (NE) e em Campos (RJ). 0 embrião disso veio com o Decreto-Lei Federal n 1.130, de 2 de março de 1939, em que pelo menos $70 \%$ dos aumentos da quota de produção de cada empresa deveriam corresponder ao processamento de matéria-prima dos fornecedores. Mas a primeira regulação das relações internas dentro do complexo viria com o Decreto-Lei Federal n 3.855, de 21 de novembro de 1941, que aprovou o Estatuto da Lavoura Canavieira. Aqui se estabelecia que as usinas não poderiam moer mais de $60 \%$ de canas próprias, garantindo assim o Executivo Federal a sobrevivência dos fornecedores.

Essa importância que o Estatuto da Lavoura Canavieira dava aos fornecedores correspondia principalmente à demanda dos antigos "senhores de engenho" nordestinos, reduzidos à condição de meros fornecedores a partir da consolidação das usinas. Isto é, a legislação procurava conter o processo de diferenciação "para baixo" que estava ocorrendo nas regiões canavieiras tradicionais, com a consolidação da usina integrada verticalmente como unidade hegemônica. Apesar de existir na regulamentação uma idealização da pequena produção, que procurava ver os fornecedores como uma classe média rural, no plano político as influências eram exercidas sobretudo pelos grandes proprietários produtores e pelos usineiros (Szmrecsányi, 1979).

De modo geral, pode-se dizer que na primeira fase da intervenção estatal, até 1945, tentou-se dirigir o efeito de algumas tendências do desenvolvimento capitalista. Um exemplo foi a tentativa de frear o processo de concentração dos capitais e a transferência da produção para a região Centro-Sul, o que não evitou, no entanto, que tais tendências acabassem prevalecendo. A intervenção estatal refletia as contradições do processo de transformação em curso, que derivavam, em grande parte, da heterogeneidade das classes hegemônicas no poder e do caráter instável do equilíbrio das forças sociais dominantes. É importante ter presente que a Revolução de 1930 representou o acesso ao poder de parcelas da burguesia e a quebra do poder hegemônico de parcelas dos grandes proprietários rurais. Entretanto, não representou uma ruptura absoluta no esquema de poder anterior, e sim um movimento acomodatício entre as antigas classes rurais e as novas classes burguesas, característico do tipo de revolução passiva que aqui vicejou (Werneck Vianna, 1999).

Com a nova orientação política após 1945, haveria um reforço do maior crescimento da agroindústria canavieira e teria início um período de maior liberalismo econômico. A mudança obedeceu, em grande medida, às pressões dos usineiros paulistas pelo aumento de sua produção, o que se deu de dois modos. Primeiro, foram autorizadas a transformação dos 
pequenos engenhos que surgiram durante a Segunda Guerra Mundial em usinas e a criação de novas usinas e destilarias. Segundo e mais importante, o Decreto-Lei Federal n 9.827, de 10 de setembro de 1946, estabeleceu que a revisão das quotas dos estados importadores devia levar em conta a demanda, a capacidade de produção e o déficit entre produção e consumo; ou seja, os estados poderiam deixar de ser importadores, atendendo ao crescimento da demanda pela sua própria oferta. Como consequência disso e da expansão do mercado consumidor em São Paulo, a produção paulista teve um crescimento muito significativo no final da década de 1940, e ocorreu uma transformação qualitativa da agroindústria canavieira do estado.

Na década de 1950 houve nova fase de expansão, determinada em boa parte pelo crescimento do mercado externo. Já com certa consolidação de seu poder econômico e político, os produtores do Centro-Sul pressionaram o Estado, na figura do IAA, diante da concorrência com os produtores do Nordeste. 0 resultado foi que, na segunda metade de 1950, finalmente o Centro-Sul foi autorizado a aumentar suas capacidades instaladas de acordo com os mercados regionais por ele abastecidos, beneficiando principalmente São Paulo, enquanto a região Nordeste foi orientada em grande parte para a exportação. Assim, atendida a demanda interna, e com a orientação para a exportação, o Brasil foi novamente colocado entre os principais exportadores mundiais. No período 1957-1961, o Brasil exportou 35,2\% da sua produção total de açúcar (Szmrecsányi, 1979).

Apesar de muitas exportações terem sido gravosas na safra 1959/1960, e de terem sido implementadas medidas restritivas, no final da década de 1950 a Revolução Cubana voltou a abrir boas perspectivas para a produção brasileira no mercado externo, em especial no norte-americano. No início da década de 1960, mais uma vez buscou-se uma ampliação da capacidade produtiva do parque industrial e das lavouras, conduzida pelo IAA. As primeiras medidas foram a criação do "Fundo de Recuperação da Agroindústria Canavieira", por meio do Decreto Federal n 51.104, de $1^{\circ}$ de agosto de 1961, e a criação do "Fundo de Consolidação e Fomento da Agroindústria Canavieira", por meio do Decreto Federal do Conselho de Ministros n 156, de 17 de novembro de 1961. Esses fundos se voltavam quase que exclusivamente para o fomento das exportações através de operações de crédito para usinas, cooperativas de fornecedores e bancos de fornecedores de cana.

Em 1963, foi formulado o "Plano de Expansão da Indústria Açucareira Nacional", que ampliou o limite global de produção das usinas do país, sendo que os estados de São Paulo e Paraná, juntos, passaram a deter quase 40\% do limite nacional. Depois, em 1964, com a criação da Comissão Executiva do IAA, foi realizada uma avaliação dos candidatos às quotas de produção, dando prioridade à concessão de financiamentos para a implantação de atividades 
agroindustriais substitutivas do café. 0 Banco do Brasil foi o grande financiador da erradicação dos cafeeiros para o plantio da cana, dispensando para tanto o registro dos plantadores de cana no IAA, o que gerou uma "verdadeira corrida para a cana", consagrando definitivamente o estado de São Paulo: o programa tinha como objetivo ampliar a produção em até 100 milhões de sacas em 1971 e, para alcançar isso, as quotas foram reajustadas em quase 100\% para esse estado (Szmrecsányi, 1979), sendo autorizada ainda a instalação de mais 50 usinas.

0 resultado disso, junto com fatores externos como a queda acentuada do preço do açúcar no Mercado Livre Mundial, foi uma crise de superprodução, que atingiu seu ápice na safra 1965/1966. Principalmente nos estados de São Paulo e do Rio de Janeiro, criou-se uma situação de intenso conflito entre os fornecedores e os usineiros, levando à necessidade de intervenção do Governo Federal. Uma das explicações para esse confronto é o fato de que o IAA passava, desde 1963, por um processo de debilitação de sua autoridade, ao ter parte de suas funções transferidas. Destaca-se nesse processo a perda de sua competência na supervisão das relações de produção entre os trabalhadores, fornecedores e usineiros com a promulgação do Estatuto do Trabalhador Rural - ETR (Idem).

0 mecanismo de limitação da produção introduzido em 1933 não impediu, portanto, que a área plantada, a produção de açúcar e os rendimentos continuassem crescendo; apenas conteve aumentos vertiginosos. Neste sentido, as contradições da ação do Estado também se manifestaram no fato de que a grande expansão da produção paulista se fez sob o marco de uma política que, aparentemente, queria contê-la. Ao não permitir que as regiões concorressem na base do preço e ao procurar manter uma produção regional, apesar dos seus maiores custos, o Estado acabou favorecendo a apropriação de uma "renda diferencial" de caráter permanente por parte dos usineiros do Centro-Sul, permitindo uma grande expansão da sua capacidade produtiva.

Além disso, o sistema de quotas de produção não significou um verdadeiro limite à expansão paulista, mas funcionou como proteção às empresas já instaladas, como uma verdadeira "barreira à entrada" no setor. Favoreceu, ainda, o crescimento potencial das empresas já estabelecidas, o que representou uma proteção da concorrência e uma reserva de recursos produtivos. Mesmo que as características técnicas da produção possam ter significado uma limitação à concentração técnica, existiu um importante processo de concentração econômica - os quatro principais grupos empresariais chegavam a dominar quase $40 \%$ da produção do estado no período 1966-1971.

Resumindo, houve um crescimento do número de empresas em São Paulo mais intenso do final dos 1940 ao início de 1950 e um aumento de tamanho dessas empresas de forma mais acentuada a partir da segunda metade da década de 1950. Começou a ser consolidado, 
a partir daí, um processo irreversível de transferência da hegemonia da agroindústria canavieira para a região Centro-Sul. Ao mesmo tempo, gradativamente foi consolidado o poder dos usineiros e suas associações como classe hegemônica dentro do "complexo" canavieiro.

\section{DESPROTEÇÃO SOCIAL E REESTRUTURAÇÃO DO TRABALHO NO CANAVIAL DO PRÉ-1964}

S e, por um lado, a economia produtora sucroalcooleira contava com grande intervenção do Estado, por outro, na ponta do trabalhador, o quadro era bem diverso. Apesar da existência de uma grande heterogeneidade das classes hegemônicas no poder e da instabilidade das forças sociais dominantes, como já apontado, os trabalhadores e trabalhadoras rurais ficavam sempre em posição mais vulnerável, sujeitos a formas de submissão no sistema produtivo que em muito dificultavam as práticas de representação, em especial via sindicatos de trabalhadores rurais. Uma dessas formas foi justamente utilização dos seus poucos direitos legais adquiridos: o Estatuto da Lavoura Canavieira instituiu uma arrecadação de $\operatorname{Cr} \$ 1,00$ por tonelada de cana para a constituição de um fundo voltado para a assistência à produção, e "contratos-tipos", a juízo do IAA, previam assistência médica e hospitalar e ensino primário gratuito às crianças em idade escolar. 0 Decreto-Lei Federal $n^{\circ} 6.969$, de 19 de outubro de 1944, incluiu a oferta de assistência médico-legal para os colonos e trabalhadores rurais, e 0 Decreto-Lei Federal 9.827, de 1946, redefiniu as condições de assistência aos trabalhadores.

Na prática, contudo, os serviços de assistência médica aos colonos e trabalhadores rurais foram estabelecidos em grande parte no âmbito das entidades patronais ou de suas entidades representativas. Exemplar disto foi a experiência de Campos dos Goytacazes (RJ), onde o Sindicato Agrícola de Campos² criou em 1948 o Serviço de Assistência Médico-Social, substituído no mesmo ano pela Associação Fluminense dos Plantadores de Cana (Asflucan), onde se criou o Departamento de Assistência Médico-Social (Neves, 1997).

Essas formas de submissão se agravariam nos anos seguintes, especialmente a partir da década de 1950 que, como já vimos, expandiu a produção da cultura de cana-de-açúcar ao mesmo tempo em que transferia para o Centro-Sul a hegemonia da agroindústria canavieira num momento de crescimento da demanda do mercado externo. Nessa época, o IAA recebeu uma estrutura administrativa mais ampla e mais complexa e foi um dos indutores importantes do crescimento no setor, que não apresentava ainda riscos de superprodução em médio prazo: a absorção da produção não era preocupação por conta das exportações da cana-de-açúcar para a produção do álcool direto ou estocagem de açúcar ou do aumento da demanda do álcool como combustível auxiliar, denominado álcool anidro (Szmrecsányi, 1979). 
Em Campos dos Goytacazes, a expansão da capacidade instalada das usinas foi estimulada por uma série de políticas: programas especiais de crédito do Ministério da Agricultura para a compra de tratores, caminhões e jipes importados, através do Fundo de Mecanização da Lavoura; criação do Plano Estadual de Mecanização da Lavoura no âmbito da Secretaria de Agricultura do Estado do Rio de Janeiro; ampliação de créditos pelo IAA para os fornecedores através do Serviço de Mecanização do Banco dos Lavradores do Estado do Rio de Janeiro; e obras de infraestrutura como a pavimentação da estrada que ligava Campos a Niterói e abertura de estradas conectando municípios circunvizinhos (Neves, 1997).

A expansão da produção, traduzida na expansão das áreas de cultivo, na mecanização e nas modificações técnicas da produção e no processo de concentração industrial e de terras, ocasionou uma forte alteração da organização sociopolítica de Campos. Usineiros e plantadores de cana ampliaram a apropriação da força de trabalho, intensificando-a e reduzindo seu valor através de formas de contratação temporária e de trabalho clandestino. Isto se deu, basicamente, por dois fatores: a concentração de propriedades de terra pelos plantadores através da expropriação dos colonos e dos moradores, e a aquisição de instrumentos mecanizados pelos lavradores com mais recursos (Idem).

Na realidade, a expropriação dos colonos se iniciou a partir do Estatuto da Lavoura Canavieira de 1941 e do Decreto-Lei 6.969 de 1944 que, ao conferirem a eles certos direitos legais, impeliram os proprietários a se livrarem desses compromissos. Com o processo de mecanização, interessava ainda mais aos empregadores a criação de alternativas de imposição de mecanismos extras de apropriação de sobretrabalho. Casos arquivados no Sindicato dos Trabalhadores Rurais documentando situações de falecimento de colonos em que sua família reivindicava a manutenção ou indenização da benfeitoria indicavam alguns dos dissídios envolvendo o processo de expropriação (Idem). A intermediação de situações de conflito relativas à permanência na terra de famílias de colonos era feita pelos dirigentes sindicais ou diretamente através do IAA, mesmo antes da promulgação do Estatuto da Lavoura Canavieira. As primeiras iniciativas para constituir um mediador recaíam sobre o presidente do sindicato, que visitava ele próprio a lavoura e apresentava uma proposta. Caso não se chegasse a bom termo, o processo era encaminhado ao IAA (Idem).

Também no processo de extinção da morada concorreram fatores como as alternativas criadas pelo uso de instrumentos mecanizados, mudanças nas condições técnicas da produção, uso extensivo do solo para cultura especializada da cana e exploração de sobretrabalho mediante baixa remuneração. 0 rompimento da relação de morada implicava o reconhecimento legal do vínculo de trabalho, através da rescisão de contrato. Apesar de isso trazer algumas vantagens aos moradores (carteira assinada, salário mínimo, décimo-terceiro, férias 
e repouso remunerado), não era uma situação de simples escolha, pois implicava a perda da casa e das lavouras de subsistência. Vantagens do moderno, vantagens do atraso, bem como suas respectivas desvantagens sob a ótica do trabalhador, pois, ao preço de se manter sob o domínio pessoal do empregador e de conservar, ainda que em condições mais precárias, uma residência, ele em algumas circunstâncias mantinha resquícios da antiga relação. ${ }^{3} 0$ acesso ao trabalho, por exemplo, e aos serviços por parte dos trabalhadores (inclusive e principalmente de assistência médica), já numa relação de moradia com residência mais afastada dos domínios senhoriais, e com o reconhecimento de alguns direitos trabalhistas, implicava dificuldades de transporte, sendo recorrente o uso da bicicleta (Idem).

Mesmo com algumas provisões a mais no âmbito da (des)proteção social dos trabalhadores e trabalhadoras no início da década de 1960, com os fundos de reparação e de consolidação e fomento da agroindústria canavieira, a prestação de serviços de assistência médica foi mantida nos mesmos moldes dos períodos anteriores e foi decisiva para a consolidação de uma ordem social em Campos dos Goytacazes, segundo os interesses dos grandes produtores. A partir de 1956 a Asflucan, utilizando verbas complementares oferecidas pelo IAA, construiu diversas instituições provedoras de saúde, com destaque para o Hospital dos Plantadores de Cana, inaugurado em 1963 com 70 leitos (Idem). A novidade foi que a concessão destes serviços ao mesmo tempo atribuiu direitos e motivos para que os trabalhadores reivindicassem o reconhecimento legal da relação de trabalho, pois a Asflucan demandava autorização do empregador para o atendimento em saúde, abrindo mais uma seara de disputas, em grande parte canalizada para o judiciário.

Este reconhecimento, no plano legal, dos vínculos de trabalho, é um dos fatores cruciais desta discussão. 0 crescente processo de extinção da morada e do colonato iniciados na década de 1940 fora acompanhado por uma tendência também crescente de os trabalhadores reivindicarem os direitos adquiridos frente aos seus empregadores. Estes, por seu turno, principalmente com a consolidação dos grandes produtores no período de expansão e mecanização da produção de cana a partir da década de 1950, passaram a acionar mecanismos de intensificação do trabalho e redução dos custos da força de trabalho. A legislação funcionou para os trabalhadores como uma instância externa aos agentes diretamente envolvidos, e as fissuras provocadas nas relações entre empregado e empregador foram contrapostas às novas formas de associação e mediação através dos sindicatos (Idem).

A partir da década de 1950, quando a exploração da força de trabalho começou a se intensificar, foram frequentes os episódios de reivindicação de alguns direitos como o reajuste de salário mínimo e os descontos de aluguel das casas concedidas. Foi na década de 1960, contudo, que esta exploração se aprofundou ainda mais, especialmente a partir do Estatuto 
do Trabalhador Rural editado pela Lei Federal 4.214, de 2 de março de 1963. O ETR, apesar de ter promovido avanços significativos ao romper - ao menos em suas bases objetivas - com os conteúdos clientelísticos e patrimoniais das relações trabalhistas (Costa, 1996: 80), deixava aberto o problema da fiscalização das relações de trabalho, que naquele momento perdia a figura do IAA, enquanto ainda era latente o conflituoso processo de reconhecimento dos sindicatos rurais. Estava formado, então, o terreno sobre o qual viria o contexto da ditadura no canavial brasileiro, que iria alterar profundamente as relações de trabalho e de produção e, ao mesmo tempo, aprofundar contradições de longa duração.

\section{A DITADURA NO CANAVIAL BRASILEIRO}

partir da segunda metade dos anos 1960 ocorreu uma mudança na orientação da po-
lítica destinada ao setor, fundamentada na convicção de que o crescimento da agroindústria canavieira só poderia ocorrer por meio das exportações (reforçando uma estratégia seguida desde a década de 1950), o que implicava tornar sua produção mais competitiva no que se refere a custos e rendimentos (Szmrecsányi, 1979).

Mas esta mudança respondeu, também, à nova correlação de forças em que passou a existir uma relação direta entre a predominância do capital agroindustrial e as políticas modernizadoras. Assim, a consolidação da hegemonia do capital agroindustrial tendia a superar as contradições da intervenção do Estado no setor, que derivavam, em última instância, do caráter incompleto da transição burguesa. 0 poder dos usineiros paulistas e de suas organizações para obter políticas favoráveis parece ter aumentado significativamente no pós-64.

0 primeiro indicador dessa fase foi a promulgação da Lei Federal $n^{\circ} 4.870$, de $1^{\circ}$ de dezembro de 1965, que instituiu, entre outras coisas, o Fundo Especial de Exportações, que seria dedicado a modernizar o setor e aumentou o financiamento destinado ao setor. Também importante foi a Resolução n 1.974, de 28 de julho de 1966, que dispôs sobre a comercialização do açúcar no mercado interno durante a safra 1966/1967, dividindo o território nacional em duas regiões açucareiras: Norte-Nordeste e Centro-Sul.

A verdadeira consolidação da política de modernização só ocorreria, no entanto, a partir de 1969. Para a política exportadora eram necessárias uma demanda crescente no mercado internacional e uma oferta suficiente em quantidade e qualidade, a custos competitivos (Idem). A demanda foi criada por condições extremamente favoráveis no mercado externo no período 1969-1974. Por outro lado, as principais medidas de modernização foram a criação do Programa Nacional de Melhoramento da Cana-de-Açúcar (Planalsucar) e do Programa de Racionalização da Agroindústria Açucareira, ambos em 1971. ${ }^{4}$ A criação do Planalsucar significou mais parti- 
cipação do IAA nas atividades de pesquisa tecnológica, participação essa que, mesmo sendo atribuição antiga do instituto, não havia sido consolidada, e ganhou ainda mais importância com um convênio com a Empresa Brasileira de Pesquisa Agropecuária (Embrapa) em 1974.

O Programa de Racionalização estabeleceu estímulos para a fusão, incorporação e relocalização das usinas. Também houve créditos para a modernização da atividade agrícola e para a concentração da quota de fornecimento de cana. Além disso, o critério de revisão de quotas passaria a considerar os rendimentos industriais das unidades produtivas com relação à média regional; as empresas mais eficientes teriam aumentos de quotas, favorecendo assim as empresas mais dinâmicas. Procurava-se alcançar uma redução de custos por meio das economias de escala derivadas da concentração empresarial.

Entretanto, é importante destacar que boa parte das unidades que se fundiram durante o Programa já era propriedade dos grupos incorporadores; buscava-se assim eliminar os obstáculos à concentração técnica derivados da legislação açucareira para completar um processo de concentração econômica que já tinha ocorrido no período anterior. 0 efeito do Programa foi o da concentração industrial, beneficiando os estados que possuíssem melhores condições de produção e cancelando a inscrição no IAA de usinas relativamente improdutivas. Em 1971, de 43 usinas canceladas, 36 eram da região Norte/Nordeste (Idem).

As exportações passaram a ser mais significativas a partir da vigência do Acordo Internacional do Açúcar em 1969. Em 1974, o crescimento do valor das exportações chegou a transformar o açúcar no principal produto na pauta de exportações do país, o que significou um maior alcance das medidas modernizadoras, pois tanto o Programa de Racionalização quanto o Programa de Melhoramento foram financiados por recursos advindos do Fundo Especial de Exportação, que apresentou saldos positivos em fins de 1968 (Idem). Os recursos eram oferecidos às empresas do setor em condições extremamente favoráveis: ausência da correção monetária, juros baixos e prazos de 12 a 15 anos.

0 resultado dos programas, junto com a situação favorável do mercado externo, foi o aumento da produção em 31\% da safra 1970/1971 até a safra 1974-1975. No mesmo período, o número de usinas em funcionamento diminuiu 17\%, reforçando os dados sobre a concentração do período. Os critérios de distribuição do contingente oficial de produção e as políticas de preços que criavam grande defasagem do preço da cana com relação aos demais produtos geraram insatisfações por parte dos fornecedores, causando um abandono por parte deles, para o cultivo de outros produtos, especialmente no Centro-Sul. Isto somente foi contido com a fixação de preços da safra 1974/1975.

Em 1974, contudo, com a expiração do Acordo Internacional do Açúcar e o aumento da participação de adoçantes no mercado, o preço do produto no mercado internacional 
despencou (Idem), e, com o fechamento das boas perspectivas do mercado internacional e a expansão da capacidade instalada no período anterior, a agroindústria canavieira teve que enfrentar novamente uma crise de superprodução, cuja solução seria a orientação para a produção de álcool para o mercado interno a partir do advento do Proálcool em 1975. Mais uma vez, a articulação dos interesses do capital agroindustrial com o Estado conseguiu reorganizar a ênfase de sua produção, que, sem abandonar a participação na cesta básica de consumo do mercado interno, passou a se dedicar principalmente ao álcool. Criou-se um nexo com a expansão do setor automobilístico e uma inserção na matriz energética nacional, trazendo novos atores à participação no setor.

A partir de 1974, a agroindústria canavieira passou a trabalhar com capacidade ociosa devido à queda dos preços do açúcar. Desta vez a produção de álcool seria a estratégia para o problema, mas com nova dimensão devido à coincidência da primeira crise do petróleo em 1973, quando o barril de petróleo no mercado internacional se elevou de US\$ 3 para cerca de US\$ 12. Isso fez com que os grupos vinculados à agroindústria canavieira pressionassem a escolha desta matéria-prima como fonte energética alternativa. Foi promulgado, então, o Decreto Federal n 76.593, de 14 de novembro de 1975, instituindo o Programa Nacional do Álcool (PNA), conhecido como Proálcool.

Este programa foi conduzido pela Comissão Nacional do Álcool, criada para esta finalidade, com representação de vários Ministérios, afastando o IAA do comando e controle de um ramo que sempre estivera sob sua jurisdição, e deixando a comercialização da produção para a Petrobrás. Assim, caberia ao setor privado a produção do álcool e à Petrobrás o controle sobre a comercialização do produto. Quatro mecanismos foram utilizados para promover a produção do álcool: a) estabelecimento de preços remuneradores em paridade com o preço do açúcar; b) empréstimos para investimentos em condições favoráveis; c) garantia da compra do produto pela Petrobrás; d) medidas para incrementar o consumo de álcool combustível como a mistura obrigatória à gasolina.

Com o segundo "choque" do petróleo em 1979 e o novo aumento do preço do barril (desta vez subindo para US\$34), houve um aprofundamento do programa para sua segunda fase. Passou-se a enfatizar a produção do álcool hidratado para ser utilizado como único combustível, com o comprometimento da indústria automobilística a realizar as modificações necessárias para transformar os motores, produzindo carros movidos exclusivamente a álcool. Isto representou significativa expansão para o mercado do álcool.

Esses estímulos levaram a um rápido crescimento da área plantada com cana (de 619 mil hectares em 1975 para dois milhões em 1985 só em São Paulo). Em nível nacional, a produção dobrou no mesmo período. Esse aumento foi causado pelo crescimento da produção 
de álcool combustível: de 544 milhões de litros em 1975/1976 para 11 bilhões de litros em 1985/1986, segundo estatísticas do IAA (Cavalcanti, 1992).

0 álcool transformou-se no carro chefe do complexo e garantiu a continuidade do crescimento da agroindústria canavieira ameaçada por uma crise de realização no mercado externo. 0 crescimento da sua produção permitiu a plena utilização da capacidade de esmagamento instalada no período 1971-1974 e concentrou-se em São Paulo, que detinha 65\% da produção nacional de álcool, reforçando o poder dos tradicionais grupos usineiros paulistas.

Até 1979 a maior parte de produção de álcool concentrava-se nas destilarias anexas às usinas de açúcar. A partir daí, foi estimulada a instalação das destilarias "autônomas", que na maioria das vezes eram de dimensões menores que as grandes usinas de açúcar e álcool, mas, ainda assim, estas só alcançaram 30\% da produção na safra 1984/1985. Assim, enquanto a escala média da agroindústria sucroalcooleira paulista praticamente dobrou durante 0 Proálcool, as oito maiores empresas desse estado tiveram um crescimento da escala média de $168 \%$.

A segunda fase do Proálcool representou enorme crescimento dos investimentos e projetos quando comparada com a primeira fase, sendo que a maior parte do financiamento veio de recursos do governo (Idem). 0 grande aumento da produção de álcool deu-se à custa de uma expansão sem precedentes da monocultura canavieira, especialmente no estado de São Paulo. Com o álcool concorrendo no mercado automobilístico, houve um enfraquecimento da Petrobrás, que por sua vez retardou seus pagamentos aos produtores de álcool e abandonou as estocagens do produto no final de década de 1980 (Szmrecsányi \& Moreira, 1991).

Com isso, ao avaliarmos o Proálcool em 1980 pela bibliografia descrita, concluímos que foi possível alcançar as metas de produção previstas. Porém os outros objetivos estabelecidos quando da formulação do Programa - diminuição dos desequilíbrios regionais, fixação do homem no campo, diminuição do desemprego rural e da distribuição de renda - não só não foram alcançados como os problemas foram agravados durante o período do Proálcool. Isto porque o Programa se baseou, em grande parte, no reforço da capacidade instalada da agroindústria canavieira, espelhando as distorções já patentes neste setor.

O Proálcool foi projetado para ser um investimento rentável na hipótese de o álcool precisar concorrer com a gasolina. Entretanto, a manutenção de preços relativamente baixos para o petróleo desacreditou previsões mais alarmistas, tornando o álcool uma alternativa pouco viável se comparado com os preços da gasolina que, já na década de 1990, estavam mais vantajosos.

A redução relativa do preço do álcool, e consequentemente do preço pago pela matéria-prima, refletiu-se numa crise do abastecimento de cana para o processamento agroin- 
dustrial. Isto se deveu à falta de investimento na renovação das plantações e ao afastamento de muitos fornecedores da lavoura, que tinham maior flexibilidade para usar seus recursos produtivos e podiam responder mais rapidamente a variações de preço. Além disso, em 1985 foi eliminada uma linha especial de crédito para custeio da produção de cana, e esta lavoura foi incluída nos recursos gerais do crédito rural, que também foram bastante reduzidos. Assim, os pequenos e médios fornecedores, que em geral tinham custos unitários de produção maiores do que os da cana das usinas, não puderam absorver da mesma forma a queda acentuada da rentabilidade. Houve um aumento no grau de integração vertical da atividade agrícola, e algumas fases do processo produtivo passaram a ser realizadas com assistência das usinas (colheita, transporte, entre outras), criando uma maior dependência do fornecedor em relação à usina.

\section{Desproteção Social E ReESTRUTURAÇÃo do TRABALHO NO CANAVIAL DA DITADURA}

ssim como ocorreu com relação aos fundos criados em 1961 que previam financia-
mentos dedicados à assistência social, os novos financiamentos criados geraram problemas do ponto de vista institucional e das próprias relações sociais. Boa parte dos serviços de saúde e educação continuava a cargo dos empregadores, conferindo a eles um poder de influência enorme sobre a vida dos trabalhadores e trabalhadoras, de grande profundidade social, o que significava em última instância um comprometimento da cidadania rural.

A expansão da produção no período (em especial dos anos 1960-1968) ocorreu antes mesmo da criação de programas mais amplos de proteção social. A partir de meados da década de 1960, intensificou-se toda a cadeia produtiva, principalmente o corte manual da cana, por motivos que serão discutidos a seguir.

Uma vez mais, tomando como horizonte a experiência de Campos dos Goytacazes no norte fluminense, há que se destacar dois fatores concomitantes importantes que concorreram para transformar as condições de trabalho nos canaviais. 0 primeiro foi estimulado pela mecanização, e o segundo, aprofundando ainda mais a interdependência entre indústria e agricultura, foi o aprimoramento da qualidade da produção da cana, conforme apontado anteriormente.

Já em 1967, o IAA perdeu poder de intervenção quando foi criado o Conselho Monetário Nacional (CMN), que passou a coordenar boa parte da política econômica do país (Neves, 1997). Este rearranjo econômico de grandes proporções forçou uma alteração da organização política antes representada pelo poder corporativo dos fornecedores e usineiros. A incorpora- 
ção do moderno no plano econômico se fez acompanhada de uma tentativa - em parte bem-sucedida - de submeter os trabalhadores a um novo cálculo racional, mas se valendo ainda de fórmulas políticas antigas. Este novo cálculo veio com a introdução de novas formas de produção naquele contexto da década de 1970, em que técnicos e agrônomos, a serviço das políticas nacionais do Estado e por meio de instituições como a Empresa Brasileira de Pesquisa Agropecuária, Empresa Brasileira de Assistência Técnica e Extensão Rural, Comissão Nacional de Pesquisa Agropecuária e de Assistência Técnica e Extensão Rural e Comissão Coordenadora da Política Nacional de Crédito Rural buscaram criar a figura do agricultor moderno (Idem).

Mas essa tentativa esbarrou no plano concreto das relações sociais e políticas já estabelecidas, provocando uma modernização seletiva e incompleta. Seletiva porque os serviços de assistência técnica e científica e os instrumentos necessários para a modernização somente podiam ser adquiridos por meio de grandes investimentos de capital, ou seja, os plantadores e usineiros foram os principais beneficiados. 0 uso intensivo de instrumentos mecanizados e a especialização do cultivo da cana exigiram cada vez mais trabalhadores temporários, que se dedicavam basicamente às tarefas menos qualificadas de limpa e de corte da cana. Com a plantadeira, por exemplo, poucos trabalhadores se destinavam ao plantio. Os plantadores tentavam minimizar os custos com a mão de obra, recorrendo ao uso da ilegalidade do vínculo de trabalho: faziam recair sobre os trabalhadores os efeitos dos riscos que eles deviam enfrentar, como a transferência do aumento do custo de produção para o preço da cana.

Estes fatores, decorrentes da exclusão da democracia política e social típica do regime autoritário, caracterizaram em larga medida a incompletude da modernização. Resultou neste período que, desta combinação de fatores, as máquinas e as tecnologias concorreram a favor da produção, e os trabalhadores continuaram a exercer a função antiga do trabalho - aquela de baixa qualificação e exaustivo esforço físico ditado sob o ritmo das máquinas, com relações de trabalho ora clandestinas, ora legalmente (mas nem sempre efetivamente) reconhecidas.

As unidades de produção, até mesmo aquelas com menor absorção das tecnologias, não mais necessitavam de muitos funcionários permanentes. Os donos de terras já exerciam a função de administradores, e o trabalho permanente necessário era geralmente mais qualificado (supervisão de trabalhadores, tratoristas, contadores, administradores etc.). A força de trabalho temporária, já com residência fora dos domínios patronais, se fazia necessária para a limpa e o corte da cana, atividade esta facilitada pela logística de transporte das usinas que, ao adquirir veículos como ônibus, passaram a contratar as turmas de cortadores, gerenciando esta atividade em parceria com os produtores de cana.

Seus salários eram, em princípio, estabelecidos por acordos entre o Sindicato Rural e o Sindicato de Trabalhadores que em grande parte dos casos não eram cumpridos, levando 
a um número significativo de casos registrados na justiça trabalhista. Acessando os registros contidos no Sindicato dos Trabalhadores Rurais de Campos dos Goytacazes, Neves (1997) identificou um aumento expressivo no número de trabalhadores que solicitaram a intermediação do sindicato para a justiça trabalhista, especialmente a partir da incorporação regulada dos trabalhadores rurais.

Isto se deu, primeiro, pelo Decreto-Lei Federal n²76, de 28 de fevereiro de 1967, que criou o Fundo de Assistência e Previdência ao Trabalhador Rural (Funrural) ${ }^{5}$ e passou a prever o custeio da assistência médica do trabalhador e de seus dependentes no âmbito do Instituto Nacional de Previdência Social (INPS). Depois, em 1971, quando foi criado o Programa de Assistência ao Trabalhador Rural (Prorural), sendo este o primeiro programa mais amplo de assistência. Suas prestações compreendiam a aposentadoria por velhice, aposentadoria por invalidez, pensão, auxílio-funeral, serviço de saúde e serviço social.

Em 1974, mesmo ano em que o Ministério da Previdência foi desmembrado do Ministério do Trabalho, o Funrural, vinculado neste momento ao Ministério da Previdência, foi ampliado, passando a contemplar as prestações por acidente do trabalho, financiadas por uma contribuição incidente sobre o valor comercial dos produtos agropecuários em sua primeira comercialização, conforme a Lei Federal n 6.195, de dezembro de 1974. Além do auxílio-doença, ficaram previstos a assistência médica e, em colaboração com o INPS, programas de reabilitação profissional.

Com a criação do Sistema Nacional de Previdência e Assistência Social em 1977, 0 INPS manteve os benefícios concedidos ao Funrural e ao Prorural, e os decorrentes de acidentes de trabalho, incluindo assistência complementar, reeducativa e de readaptação profissional aos trabalhadores rurais. Ao Instituto Nacional de Assistência Médica da Previdência Social (Inamps), criado neste momento, caberia a prestação de serviços de saúde e assistência médica a estes trabalhadores.

Apesar destas mudanças que se aceleraram na década de 1970, o Ministério do TrabaIho preservou uma centralidade em matéria de segurança e saúde dos trabalhadores, com algumas mudanças. Grande parte do Capítulo V do Título II da CLT, denominado "Da Segurança e Medicina do Trabalho", passou por uma reformulação por meio da Lei Federal n 6.514, de 22 de dezembro de 1977. Além de manter o Ministério do Trabalho como órgão fiscalizador por excelência das condições de realização do trabalho, esta reformulação delegou a ele inúmeras e extensas competências para regulamentar (normatizar) e complementar as normas do capítulo, como, por exemplo, a fiscalização do cumprimento das normas de segurança e saúde do trabalho, a imposição de penalidades cabíveis pelo descumprimento das normas constantes no capítulo, a obrigatoriedade da notificação das doenças profissionais, o estabelecimento de diversas condições de segurança e higiene no local de trabalho, e muitas outras. 
Logo após esta reformulação do Capítulo V da CLT, com ampla delegação normativa conferida ao Ministério do Trabalho, este editou a Portaria $n^{\circ}$ 3.214, de 8 de junho de 1978, que aprovou as Normas Regulamentadoras relativas à segurança e saúde do trabalho, passando a ser o principal instrumento normatizador que orienta as ações de inspeção do trabalho.

Mas a delegação normativa e as próprias normas continuaram (e continuam) sendo distintas para os trabalhadores rurais, apesar do princípio da isonomia entre direitos de trabalhadores urbanos e rurais previsto na Constituição de 1988. A lei que rege até hoje as relações de trabalho rural, e que revogou o Estatuto do Trabalhador Rural (Lei 4.214/1963), é a Lei Federal n 5.889, de junho de 1973, e não a CLT (esta é aplicável somente no que não colidir com a Lei 5.889). Ela prevê, basicamente, duas espécies de contrato de trabalho rural: por prazo indeterminado e por prazo determinado; este último inclui o contrato de safra, que tem sua duração dependente de variações estacionais da atividade agrícola (como, por exemplo, a soja, o algodão, o milho e a própria cana-de-açúcar), geralmente não excedendo um ano de duração.

Toda esta composição da seguridade social e da regulação do mercado de trabalho, a partir especialmente da década de 1970, tornou-se, aos olhos hodiernos, sedimentações passivas que condicionaram a vida dos trabalhadores e trabalhadoras. Como vimos, são vários os elementos explicativos que nos ajudam a compreender uma cultura institucional que sobreviveu e se transformou ao longo do tempo. Se o direito à saúde, à previdência e assistência social foi universalizado constitucionalmente em 1988, as instituições correspondentes aos três pilares da seguridade social não parecem ter criado uma novíssima relação com o mercado e 0 ambiente de trabalho. Encontramo-nos, ainda, diante de dias de um futuro esquecido.

\section{Notas}

1 Esta categoria permeia o trabalho, pois viabiliza a demonstração do papel das variáveis de mudança e conservação no andamento de nossa história, como um critério interpretativo em que as sedimentações passivas do passado condicionam e por vezes comprometem as propostas de mudança. Estas, por seu turno, ao processar mudanças (como por exemplo com nossa Constituição de 1988), podem arrastar uma transformação passiva da sociedade, mantendo compromissos com o mundo pretérito, origem do binômio "conservar-mudando", quando em chave menos permissiva à mudança, e "mudar-conservando", com sinal contrário ao andamento anterior.

20 poder político dos grandes produtores se estendia desde as entidades de representação política, como 0 Sindicato Agrícola de Campos, até as instituições econômicas, como o Banco dos Lavradores (Neves, 1997).

3 Sobre este ponto, uma narrativa de referência é a de Sigaud (1996), ao tratar dos conflitos nos engenhos das zonas canavieiras de Pernambuco em meados da década de 1990, em que o mundo dos direitos também entrou de forma transformística no mundo da cultura dos trabalhadores, dos sindicatos, engenhos e produtores rurais. 
4 Já antes do lançamento dos programas, em 1969, foram criados o Laboratório Agroindustrial de Piracicaba e a Estação Experimental de Cana de Araras, ambos no estado de São Paulo. A Estação tinha por objetivo a criação de novas variedades de cana e a pesquisa nas áreas de mecanização agrícola, irrigação, uso de herbicidas, adubação, entre outros (Idem).

5 A origem jurídica do Funrural é o ETR, destinado, entre outras coisas, à prestação de benefícios aos trabaIhadores rurais e seus dependentes.

\section{REFERÊNCIAS BIBLIOGRÁFICAS}

CARDOSO, Adalberto Moreira; LAGE, Telma. As normas e os fatos. Desenho e efetividade das instituições de regulação do mercado de trabalho no Brasil. Rio de Janeiro: Editora FGV, 2007.

COSTA, Luiz Flavio de Carvalho. Sindicalismo rural brasileiro em construção. Rio de Janeiro: Forense Universitária e Edur, 1996.

; MARINHO, Ricardo José de Azevedo. A formação do moderno sindicalismo dos trabalhadores rurais no Brasil. In: COSTA, Luiz Flávio de Carvalho, FLEXOR, Georges e SANTOS, Raimundo (Org.). Mundo rural brasileiro: ensaios interdisciplinares. Rio de Janeiro: Mauá X/ Seropédica: Edur, 2008.

; MARINHO, Ricardo José de Azevedo. A constitucionalização do sindicalismo rural brasileiro. In: MOREIRA, Roberto José; BRUNO, Regina Landim (Org.). Dimensões rurais de políticas brasileiras. Rio de Janeiro: Mauad X/ Seropedica: Edur, 2010.

CAVALCANTI, Guilherme de Albuquerque. A dinâmica econômica do Poálcool: acumulação e crise, 19751989. Revista Brasileira de Energia, 2(1), 1992.

DELGADO, Guilherme. Previdência rural: relatório de avaliação socioeconômica. Brasília: IPEA, 1997 (texto para discussão, 477).

BELTRÃO, Kaizô Iwakami; OLIVEIRA, Francisco Eduardo Barreto de; PINHEIRO, Sonoê Sugahara. A população rural e a previdência social no Brasil: uma análise com ênfase nas mudanças constitucionais. Brasília: IPEA, 2000 (texto para discussão, 759).

LOPES, Júlio Aurélio Vianna. Apresentação. In: LOPES, Júlio Aurélio Vianna (Org.). Desafios institucionais da ordem de 1988. Rio de Janeiro: Fundação Casa de Rui Barbosa, 2014.

MARINHO, Ricardo José de Azevedo. Ministério Público do Trabalho \& sindicalismo rural no Brasil. Tese (Doutorado). Universidade Federal Rural do Rio de Janeiro, Curso de Pós-Graduação de Ciências Sociais em Desenvolvimento, Agricultura e Sociedade, 2011.

Passado e presente. In: LIMA, Jacqueline; ROBERTI, Angela; SANTOS, Edna (Org.). Pensando a História: reflexões sobre as possibilidades de se escrever a História através de perspectivas interdisciplinares. Rio de Janeiro: Letra Capital, 2013, v. 1, p. 145-154.

MARTINS, José de Souza. O poder do atraso. Ensaios de sociologia da história lenta. São Paulo: Editora Hucitec, 1994.

NEVES, Delma Pessanha. Os fornecedores de cana e o Estado intervencionista. Niterói: EDUFF, 1997. 
Trabalho agrícola: gênero e saúde. Antropolítica: Revista Contemporânea de Antropologia e Ciência Política. Niterói, EdUFF, n. 7, 1999.

SIGAUD, Lygia Maria. Direito e coerção moral no mundo dos engenhos. Estudos Históricos, 18, 1996.

SIMÕES, Tiago Martins. Políticas de previdência e saúde no trabalho e os trabalhadores e trabalhadoras canavieiras de Campos dos Goytacazes - RJ. Dissertação (Mestrado). Universidade Federal Rural do Rio de Janeiro, Curso de Pós-Graduação de Ciências Sociais em Desenvolvimento, Agricultura e Sociedade, 2013.

SZMRECSÁNYI, Tamás. O planejamento da agroindústria canavieira do Brasil (1930-1975). São Paulo: Hucitec, Universidade Estadual de Campinas, 1979.

; MOREIRA, Eduardo Pestana. 0 desenvolvimento da agroindústria canavieira do Brasil desde a Segunda Guerra Mundial. Estudos Avançados, 11(5), 1991.

; RAMOS, Pedro; RAMOS FILHO, Luiz Octávio; VEIGA FILHO, Alceu de Arruda. Dimensões, riscos e desafios da atual expansão canavieira. Brasília: Embrapa Informação Tecnológica, 2008 (Texto para discussão, 32).

WERNECK VIANNA, Luiz Jorge. A transição. Da Constituinte à sucessão presidencial. Rio de Janeiro: Revan, 1989.

1964. Estudos sociedade e agricultura. Rio de Janeiro: CPDA/UFRRJ, 2, 1994.

Liberalismo e sindicato no Brasil. Belo Horizonte: Editora UFMG, 1999.

A revolução passiva. Iberismo e americanismo no Brasil. Rio de Janeiro: Revan, 2004.

WERNECK VIANNA, Maria Lucia Teixeira. A americanização (perversa) da seguridade social no Brasil: estratégias de bem-estar e políticas públicas. Rio de Janeiro: Revan/ UCAM, IUPERJ, 1998. 